\title{
ADSORÇÃO E DESSORÇÃO ANIÔNICAS INDIVIDUAIS POR GIBBSITA PEDOGENÉTICA
}

Adélia A. A. Pozza, Nilton Curi, Luiz R. G. Guilherme, João J. G. S. M. Marques, Enio T. S. Costa e Daniela Q. Zuliani

Departamento de Ciência do solo, Universidade Federal de Lavras, 37200-000 Lavras - MG, Brasil

Paulo E. F. Motta

Embrapa Solos, 22460-000 Rio de Janeiro -RJ , Brasil

Rodrigo S. Martins

Heringer - Unidade Paranaguá, Rod. BR 277, km 10,53, 83203-970 Paraná - PR, Brasil

Luiz C. A. Oliveira*

Departamento de Química, Universidade Federal de Lavras, CP 3037, 37200-000 Lavras - MG, Brasil

Recebido em 29/1/08; aceito em 7/8/08; publicado na web em 18/12/08

\begin{abstract}
INDIVIDUAL ANIONIC ADSORPTION AND DESORPTION BY PEDOGENIC GIBBSITE. Anion adsorption/desorption dynamics was studied as individual processes on surface of particles of a gibbsitic clay. The data suggest a remarkable gibbsite role as nitrate leaching retardant in soil. The opposite behavior of gibbsite towards adsorption/desorption of silicate and phosphate suggests the need of an adequate compromise solution regarding interval and rate applications of anions in cultivated gibbsitic soils. The high $\mathrm{P}$ adsorption verified in $\mathrm{pH}$ values lower than that reported for the point of zero charge of synthetic Al-hydroxides implies that this process takes place in pedogenic gibbsites through inner sphere complexation.
\end{abstract}

Keywords: retention; anions; Al-hydroxide.

\section{INTRODUÇÃO}

O fenômeno de adsorção pode ser entendido como o acúmulo químico e/ou físico de uma substância ou material, por mecanismos químicos, na interface entre a superfície sólida e a solução. Três tipos de adsorção de ânions foram sugeridos por Hingston et $a l .:^{1}$ adsorção não específica: alguns ânions, como $\mathrm{NO}_{3}^{-}$, podem ser adsorvidos somente por superfícies carregadas positivamente, sendo fracamente retidos na camada difusa; adsorção específica de ânions de ácidos completamente dissociados, tais como $\mathrm{SO}_{4}{ }^{2-}$, os ânions são adsorvidos quimicamente, envolvendo troca de ligantes com a $\mathrm{H}_{2} \mathrm{O}$ de superfície e, adsorção específica de ânions de ácidos incompletamente dissociados, tais como fosfato e silicato (ou ácido silícico): a adsorção de tais ânions envolve troca com $\mathrm{OH}^{-}$ligante. Mais recentemente, a distinção entre diferentes tipos de adsorção tem sido feita considerando-se a adsorção específica como a formação de complexos de esfera interna, sem a presença de $\mathrm{H}_{2} \mathrm{O}$ entre o ânion e a superfície; a adsorção não específica seria a formação de complexos de esfera externa, com a presença de moléculas de $\mathrm{H}_{2} \mathrm{O}$ entre o ânion e a superfície adsorvente. ${ }^{2-4}$ As reações de adsorção ocorrem principalmente na fração argila do solo, em que os óxidos (termo inclusivo para óxidos, oxidróxidos e hidróxidos) de alumínio, ferro e manganês, entre outros, são as superfícies reativas mais representativas em solos de carga variável. ${ }^{2}$

O sulfato é sempre retido menos fortemente que o fosfato por $\mathrm{Al}(\mathrm{OH})_{3}$, numa ampla faixa de $\mathrm{pH} .{ }^{5} \mathrm{O}$ sulfato adsorvido é completamente deslocável pelo fosfato. ${ }^{6}$ Conforme Chao et al. ${ }^{7}$ isso ajuda a explicar a maior movimentação de sulfato no solo após a adubação fosfatada.

A adsorção de silício nas superfícies adsorventes dos minerais, precedente à aplicação de fosfato, pode aumentar a disponibilidade de fosfato em solos com elevada capacidade de retenção do ânion. Os ânions silicato são considerados competidores com o fosfato pelos mesmos sítios de adsorção do solo, ${ }^{8}$ de maneira que o silício pode deslocar (dessorver) o fosfato, ou ser deslocado por ele, da fase sólida para a líquida. ${ }^{9}$

Experimentos de síntese química mostram que à temperatura ambiente a gibbsita forma-se em soluções ácidas $(\mathrm{pH}<6)$, em condições de hidrólise mais lenta, ${ }^{10-12}$ concordando com a ocorrência natural de gibbsita em solos muito intemperizados e ácidos. ${ }^{11} \mathrm{~A}$ presença significativa de gibbsita tem sido constatada principalmente em Latossolos tropicais argilosos oxídicos, como aqueles situados nas chapadas do Planalto Central brasileiro. ${ }^{13-15}$ Via de regra, horizontes de solo contendo somente gibbsita são raros, ${ }^{16}$ porém, nessa região do Brasil Central alguns solos têm registrado mais de $950 \mathrm{~g} \mathrm{~kg}^{-1} \mathrm{de}$ gibbsita na fração argila. ${ }^{17}$

Tendo-se em mente que informações mais específicas sobre óxidos de Al naturais em solos são escassas e, diferentemente dos óxidos de $\mathrm{Fe}$, não existem tratamentos de dissolução seletiva que sejam específicos para óxidos de $\mathrm{Al}$ (o tratamento com oxalato de amônio $0,2 \mathrm{~mol} \mathrm{~L}^{-1} \mathrm{pH} \mathrm{3}$, no escuro, ${ }^{18}$ tem sido usado para se solubilizar seletivamente formas mal cristalizadas de $\mathrm{Al}$ de geomateriais), surge a necessidade de se ampliar o conhecimento ainda restrito sobre a gibbsita em solos. Essas lacunas de informação ocorrem especialmente no tocante à capacidade da gibbsita de adsorver ânions inorgânicos e orgânicos, com reflexos no manejo do solo e no ecossistema em geral. A identificação e seleção de solos, em que a gibbsita constitui praticamente toda a fração mineral, ${ }^{17}$ permitiram a realização desta pesquisa, utilizando-se o mineral natural de solo, contribuindo para melhor compreensão do comportamento dos óxidos de alumínio na dinâmica de íons, em sistemas naturais complexos, como solos, comparativamente ao que se conhece sobre a caulinita e os óxidos de ferro que, no conjunto, constituem a maior parte da fração argila dos Latossolos brasileiros. ${ }^{19,20}$

Os objetivos deste trabalho foram mensurar as capacidades de adsorção individual de fosfato, nitrato, sulfato, silicato, citrato e oxalato, e de dessorção dos ânions inorgânicos pela gibbsita de solo. 


\section{PARTE EXPERIMENTAL}

\section{Material}

Foram utilizadas amostras da fração argila de um Gleissolo Melânico, textura argilosa, localizado no Planalto Central brasileiro, em Uberaba (MG), altitude $930 \mathrm{~m}$, latitude 19³0', longitude $48^{\circ} 08^{\prime}$, que ocorre ao longo da linha de drenagem da chapada, cujos horizontes subsuperficiais têm a mineralogia da fração argila constituída quase exclusivamente por gibbsita, $>950 \mathrm{~g} \mathrm{~kg}^{-1} \cdot{ }^{16,17} \mathrm{O}$ horizonte selecionado foi coletado na profundidade de $65-90 \mathrm{~cm}$ e apresenta cor branca.

Amostras (50 g) de terra fina seca ao ar (TFSA) foram colocadas em béquer de $250 \mathrm{~mL}$. Adicionou-se $25 \mathrm{~mL}$ de $\mathrm{NaOH} 0,1 \mathrm{~mol} \mathrm{~L}^{-1} \mathrm{e}$ $25 \mathrm{~mL}$ de água destilada, seguindo-se o procedimento padrão para a obtenção da fração argila, a qual foi colocada em membranas de diálise para se retirar todo o $\mathrm{NaOH}$ adicionado, sendo em seguida levada ao liofilizador por $48 \mathrm{~h}$ para secagem a frio. Para simplificar e abreviar a estrutura do presente texto, utilizou-se o termo "gibbsita" no intuito de significar "fração argila separada do material de solo com mais de $95 \%$ de gibbsita".

\section{Caracterização da gibbsita}

Para a caracterização qualitativa da carga de superfície da gibbsita, procedeu-se à determinação do ponto de carga zero (PCZ), por meio da medição da mobilidade eletroforética, usando-se um aparelho Zeta-Meter System 3.0. Foram adicionadas em soluções $\mathrm{NaCl} \mathrm{0,01}$ mol L $\mathrm{L}^{-1}$, a pH inicial 3, 5, 7, 9 e 11 ajustadas previamente com $\mathrm{HCl}$ e $\mathrm{NaOH} 0,01 \mathrm{~mol} \mathrm{~L}^{-1}$, em quantidade de material suficiente para obter suspensões contendo $150 \mathrm{mg} \mathrm{L}^{-1}$ de argila, nas quais foram tomadas as médias de 20 leituras da mobilidade eletroforética para determinar o PCZ. O PCZ do material gibbsítico foi 6,4 e o pH em água desse horizonte amostrado foi 5,8 .

Os materiais foram caracterizados por difratometria de raios- $\mathrm{X}$

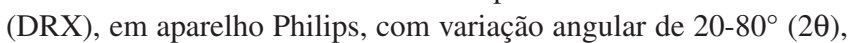
radiação de $\operatorname{CuK} \alpha\left(\lambda=1,54051 \AA\right.$ ) e velocidade de exposição de $1^{\circ} 2 \theta$ $\mathrm{min}^{-1}$; espectroscopia no infravermelho (FTIR), Digilab Excalibur, série FTS 3000; e separada do material de solo, a área superficial específica foi caracterizada por adsorção-dessorção de nitrogênio a 77 K usando o equipamento Autosorb-1, da Quantachrome.

\section{Testes de adsorção e dessorção aniônicas individuais}

Para os ensaios de adsorção, utilizaram-se tubos de centrífuga de $75 \mathrm{~mL}$, sendo que, no caso dos ânions oxalato e citrato, os tubos foram revestidos externamente com papel alumínio, para impedir a entrada de luz. Quinhentos mg da fração argila do material gibbsítico foram misturados com $50 \mathrm{~mL}$ da solução de $\mathrm{NaCl}$ (força iônica de 30 mmol L-1; $\mathrm{pH}$ inicial $=5,5 \pm 0,2$ ) conforme metodologia descrita por Marchi et al., ${ }^{21}$ contendo concentrações de $0 ; 0,15 ; 0,30 ; 0,45 ; 0,60$; 0,$75 ; 0,90 ; 1,05 ; 1,20$ e $1,50 \mathrm{mmol} \mathrm{L}^{-1}$ de nitrato, silicato, fosfato, citrato ou oxalato e $0 ; 0,075 ; 0,15 ; 0,225 ; 0,30 ; 0,375 ; 0,45 ; 0,525$; 0,60 e $0,75 \mathrm{mmol} \mathrm{L}^{-1}$ de sulfato. A diferença na concentração inicial do sulfato, em relação aos demais ânions inorgânicos, ocorreu pelo fato de que a $\mathrm{pH}$ 5,5 este ânion apresenta-se na forma divalente. Procurou-se, com isso, adicionar uma quantidade equivalente, em mmol $L^{-1}$ de cada ânion, já que os demais ânions estudados (à exceção do silicato) apresentam-se majoritariamente como monovalentes em pH próximo daquele da solução inicial $(5,5 \pm 0,2)$. Os tubos foram agitados por $24 \mathrm{~h}$, para se atingir o equilíbrio. Estas suspensões foram centrifugadas por 30 min a 3600 rpm para a separação da fase líquida da fase sólida e obtenção do sobrenadante límpido.

Os valores das concentrações de equilíbrio dos ânions inorgânicos nas fases líquidas foram determinados em espectrofotômetro UV-Vis modelo Varian - Cary 1. A leitura do nitrato foi feita diretamente no espectrofotômetro munido com cubeta de quartzo de $1 \mathrm{~mL}$, a $204 \pm$ $2 \mathrm{~nm}$, sendo que este pico foi detectado após varredura.

Para leitura do silicato, adicionou-se $0,5 \mathrm{~mL}$ de solução sulfomolibdica $\left(3,75 \mathrm{~g}\right.$ de molibdato de amônio $+5,0 \mathrm{~mL}$ de $\mathrm{H}_{2} \mathrm{SO}_{4}$ concentrado, completando-se com água destilada para o volume de $50 \mathrm{~mL}$ ) em $25 \mathrm{~mL}$ do extrato. Após $10 \mathrm{~min}$, adicionou-se $1 \mathrm{~mL}$ de ácido tartárico (20\%), agitou-se o extrato e acrescentou-se $0,25 \mathrm{~mL}$ da solução de ácido ascórbico (1,76 g de ácido em 100 mL de água). Decorrida uma hora realizou-se a leitura a $660 \pm 2 \mathrm{~nm}$.

Determinou-se o sulfato e fosfato por colorimetria. Para o fosfato utilizou-se a metodologia de Murphy e Riley ${ }^{22}$ e leitura em espectrofotômetro a $660 \pm 2 \mathrm{~nm}$; para o sulfato, utilizou-se turbidimetria com cloreto de bário e leitura a $420 \pm 2 \mathrm{~nm}$.

Citrato e oxalato foram dosados em cromatógrafo líquido de alta performance (CLAE) (marca HP-1100) equipado com coluna Zorbax (SB-C18, ODS, 4,5 mm x $25 \mathrm{~cm}$ ) e detector de arranjo de diodos. Os espectros de absorção dos ânions orgânicos foram identificados utilizando-se uma fase móvel composta de $0,25 \%$ de ácido fosfórico $\mathrm{v} / \mathrm{v}$ (pH 1,9). Para o oxalato, empregou-se leitura de $222 \pm 2 \mathrm{~nm}$, com fluxo de $1 \mathrm{~mL} \mathrm{~min}^{-1}$ e volume de injeção de $10 \mu \mathrm{L}$, obtendo-se um tempo de retenção de 1,1 a 1,2 min. Para o citrato, utilizou-se comprimento de onda de $210 \pm 2 \mathrm{~nm}$, com fluxo de $1,5 \mathrm{~mL} \mathrm{~min}^{-1} \mathrm{e}$ volume de injeção de $80 \mu \mathrm{L}$, obtendo-se um tempo de retenção de 2,6 a 2,7 min. A água utilizada nas análises foi bi-destilada e deionizada, por um sistema Millipore (Milli-Q).

As quantidades adsorvidas de cada ânion foram calculadas por meio das diferenças entre as concentrações adicionadas e as concentrações nas soluções de equilíbrio. Os dados de adsorção foram ajustados à forma linearizada da Equação de Langmuir:

$$
\frac{c}{q}=\frac{1}{k b_{(C M A)}}+\left(\frac{1}{b_{(C M A)}}\right) c
$$

em que c=concentração do íon na solução de equilíbrio $\left(\mathrm{mmol} \mathrm{L}^{-1}\right)$; $\mathrm{q}=$ quantidade adsorvida $\left(\mathrm{mmol} \mathrm{kg}^{-1}\right) ; \mathrm{k}=$ constante relacionada à afinidade da fase sólida pelo íon $\left(\mathrm{L} \mathrm{mmol}^{-1}\right) \mathrm{e} \mathrm{b}_{(\mathrm{CMA})}=$ capacidade máxima de adsorção $\left(\mathrm{mmol} \mathrm{kg}^{-1}\right)$.

A dessorção dos ânions inorgânicos foi obtida por adição de 50 $\mathrm{mL}$ de $\mathrm{NaCl} 30 \mathrm{mmol} \mathrm{L}^{-1}$ ao solo contido nos tubos de centrífuga, agitando-os por $24 \mathrm{~h}$ e analisando-se os sobrenadantes, obtidos após centrifugação para os íons nitrato, silicato, sulfato e fosfato. A dessorção foi calculada como sendo a razão entre as quantidades recuperadas, considerando-se a correção das soluções remanescentes da etapa de adsorção e as quantidades adsorvidas. Os ensaios foram realizados em triplicata, a análise de variância feita com o programa Sisvar, versão 4,6 (Build 6.1) e os gráficos feitos no programa Sigma Plot (versão 10.0).

\section{RESULTADOS E DISCUSSÃO}

\section{Caracterização da gibbsita}

A Figura 1 apresenta o difratograma de raios-X (Figura 1a) e o espectro na região do infravermelho (Figura 1b), para a gibbsita pedogenética empregada nos testes de adsorção e dessorção dos diferentes ânions.

O difratograma apresenta reflexões referentes aos principais planos cristalinos da gibbsita, com os valores de distâncias interplanares $(\mathrm{d} / \mathrm{nm})$ de 0,$484 ; 0,437$ e 0,432 , correspondendo aos planos (hkl) $\{002\},\{110\}$ e $\{200\}$, respectivamente. Os picos ou reflexões estreitas sugerem a presença da gibbsita com elevada cristalinidade. 
(a)
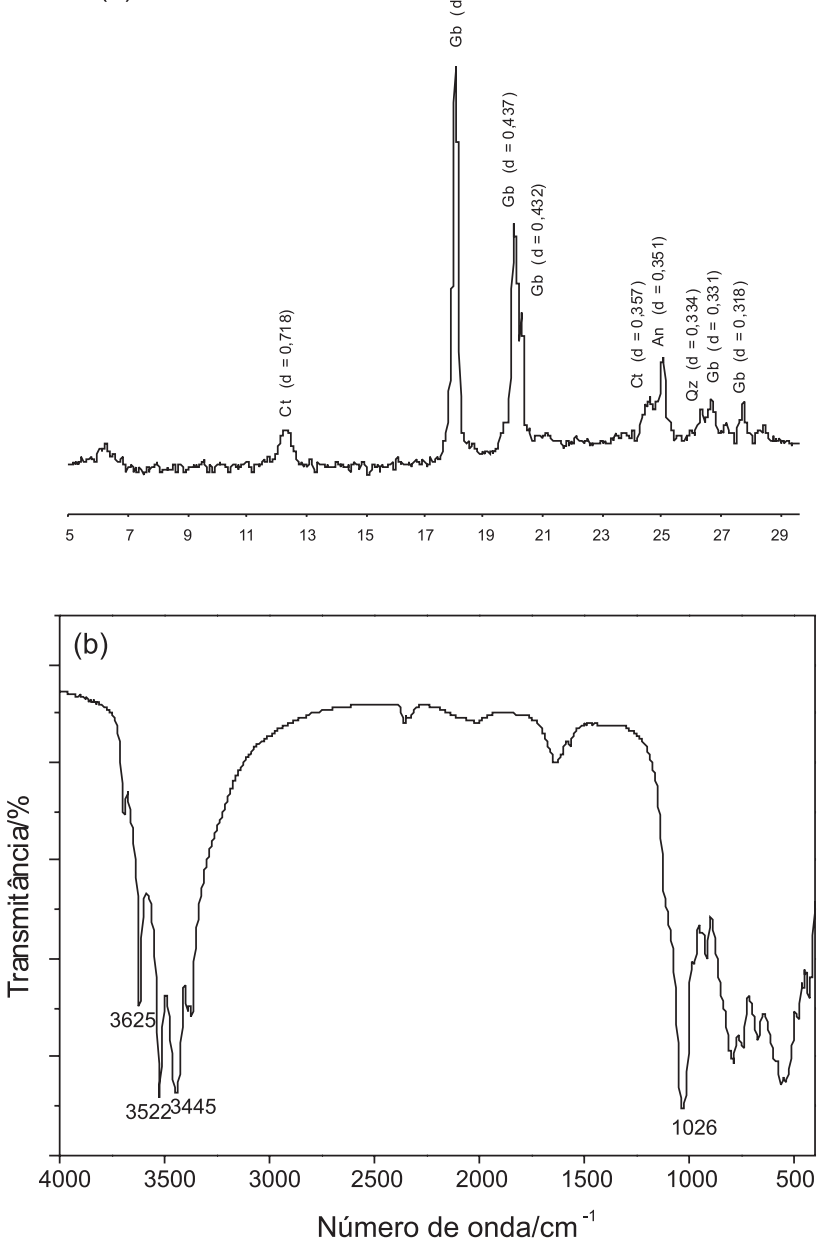

Figura 1. Difratograma de raios-X (a) e espectroscopia na região do infravermelho (b) da gibbsita (Ct=caulinita, Gb=gibbsita, $Q z=q u a r t z o$, An=anatásio

A determinação do comprimento médio coerente, MCL (Mean Coherent Lenght), empregando-se a Equação de Scherrer ${ }^{23}$ resultou em $229 \mathrm{~nm}$. Picos referentes à caulinita e ao quartzo também foram detectados, uma vez que em materiais naturais é comum a presença de tais minerais na forma de impurezas.

A análise por espectroscopia na região do infravermelho da gibbsita mostra sinal em $3462 \mathrm{~cm}^{-1}$ referente ao estiramento de grupos $\mathrm{OH}$ mono-coordenados. As bandas em 3522 e $3625 \mathrm{~cm}^{-1}$ são referentes às vibrações de hidroxilas estruturais, típicas em gibbsitas sintéticas e naturais. ${ }^{24}$ Além disso, a absorção em $1026 \mathrm{~cm}^{-1}$ deve estar relacionada à deformação angular referente à estrutura $\mathrm{Al}-\mathrm{O}-\mathrm{Al}$ da gibbsita.

A Figura 2 apresenta a isoterma de adsorção-dessorção de $\mathrm{N}_{2}$ medida a $77 \mathrm{~K}$ para a gibbsita. O valor de área superficial específica pelo BET foi de $27 \mathrm{~m}^{2} \mathrm{~g}^{-1} \mathrm{e}$ o perfil da isoterma mostrado na Figura 2 sugere a presença de um material não-poroso. ${ }^{23} \mathrm{O}$ valor baixo de área superficial pode estar relacionado à elevada cristalinidade da gibbsita observada no difratograma de raios-X.

\section{Adsorção individual}

A capacidade máxima de adsorção $b_{(\mathrm{CMA})}$ seguiu a ordem decrescente silicato $>$ fosfato $>$ oxalato $>$ sulfato $>$ citrato $>$ nitrato; a constante $k$ relacionada com a energia de adsorção seguiu a ordem silicato $>$ citra

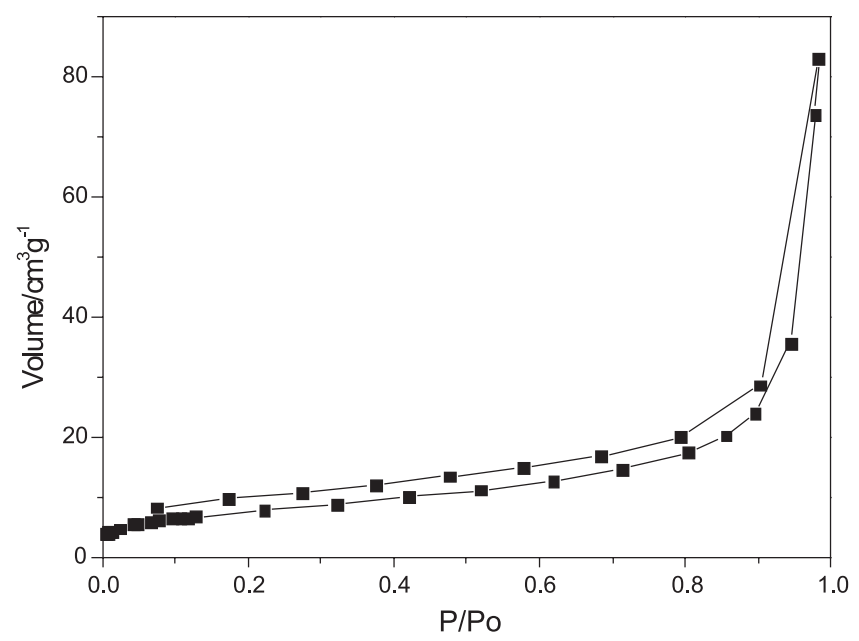

Figura 2. Isoterma de adsorção-dessorção de $N_{2}$ para a gibbsita

to $>$ sulfato $>$ oxalato $>$ fosfato $>$ nitrato (Tabela 1 ).

Vale ressaltar que essa expressão originalmente foi desenvolvida para descrever a adsorção de um gás sobre uma superfície sólida e tem sido utilizada para reações de ânions em meio líquido com constituintes de solo. ${ }^{25}$ Os autores ${ }^{25}$ consideraram, para interpretação dos parâmetros, somente a ocorrência do fenômeno de adsorção, portanto, mesmo tendo sido usado o $\mathrm{NaCl}$ e o $\mathrm{pH}$ mantido próximo a 5,5; como forma de evitar a formação de precipitado, sua possível ocorrência pode representar, além da adsorção, uma forma de decréscimo de alguns ânions na concentração de equilíbrio (e.g., fosfato e sulfato). Segundo Rietra et al. ${ }^{26}$ quimicamente, o fosfato apresenta alta afinidade para se ligar a prótons na solução. Além disso, equações de isotermas de adsorção não podem ser interpretadas para indicar qualquer mecanismo particular de adsorção, ou mesmo se a adsorção, opostamente à precipitação, tem realmente ocorrido; assim, as equações deveriam ser consideradas como modelos de ajustes de curvas com capacidade preditiva sob condições limitadas. ${ }^{27}$

$\mathrm{O}$ uso de soluções de $\mathrm{CaCl}_{2} 0,01 \mathrm{~mol} \mathrm{~L}^{-1}$ (força iônica, I, de $0,03 \mathrm{~mol} \mathrm{~L}^{-1}$ ou $30 \mathrm{mmol} \mathrm{L}^{-1}$ ) como eletrólito de fundo é bastante difundido em ciência do solo, nas mais diversas situações, incluindo experimentos de adsorção, mormente com fosfato. O objetivo é trabalhar com força iônica semelhante àquela existente em solos. Embora esses valores tenham sido originalmente sugeridos para solos de clima temperado, leituras diversas de condutividade eletrolítica (CE) de soluções de Latossolos - visando estimar I através da fórmula I $\left(\mathrm{mol} \mathrm{L}^{-1}\right)=\mathrm{CE}\left(\mathrm{dS} \mathrm{m}{ }^{-1}\right)$ x $0,0127^{28}$ - mostram que são valores também aplicáveis para Latossolos. Isso é especialmente verdadeiro em solos sob manejo mais intensivo, onde a adição de fertilizantes e corretivos tende a aumentar a concentração salina da solução do solo e, conseqüentemente, o valor de I. Ao se utilizar $\mathrm{NaCl} 30 \mathrm{mmol} \mathrm{L}^{-1}$ (força iônica, I, de $0,03 \mathrm{~mol} \mathrm{~L}^{-1}$ ou $30 \mathrm{mmol} \mathrm{L}^{-1}$ ), está se mantendo o valor de I proposto anteriormente, porém, usando $\mathrm{Na}$, ao invés de $\mathrm{Ca}$, como cátion acompanhante, para se evitar precipitações de sais de $\mathrm{Ca}$ com os ânions testados. Esta possibilidade foi previamente checada através de modelagem com o software de especiação iônica Visual Minteq. ${ }^{29}$ Assim, os resultados aqui obtidos podem ser aplicáveis a situações reais de campo.

Observou-se aumento da adsorção de todos os ânions com o aumento da quantidade adicionada (Figura 3). Os valores obtidos para adsorção de nitrato $\left(0,1 \mathrm{a} 5,5 \mathrm{mmol} \mathrm{kg} \mathrm{kg}^{-1}\right)$ são aproximadamente consonantes com a faixa observada por Dynia ${ }^{31}$ em Latossolo Vermelho-Escuro (0 a 5,5 mmol kg-1), Latossolo Roxo (0,6 a $6 \mathrm{mmol}$ $\left.\mathrm{kg}^{-1}\right)$ e Areia Quartzosa (0,2 a 3,2 mmol kg-1) e por Oliveira et al. ${ }^{30} \mathrm{em}$ 
Tabela 1. Equações linearizadas obtidas pelo ajuste de dados de adsorção de ânions pela gibbsita com o respectivo coeficiente de determinação $\left(\mathrm{R}^{2}\right)$, capacidade máxima de adsorção $\mathrm{b}_{(\mathrm{CMA})}$ dos ânions $\left(\mathrm{mmol} \mathrm{kg}^{-1}\right)$ com suas respectivas energias de adsorção $(\mathrm{k})$

\begin{tabular}{|c|c|c|c|c|}
\hline Ânion & Equação $0^{(*)}$ & $\mathrm{R}^{2}$ & $\begin{array}{l}\mathrm{b}_{(\mathrm{CMA})}{ }^{(* *)} \\
\mathrm{mmol} \mathrm{kg}{ }^{-1}\end{array}$ & $\begin{array}{c}\mathrm{k}^{(* *)} \\
\mathrm{L} \mathrm{mmol}^{-1}\end{array}$ \\
\hline \multirow{3}{*}{ Nitrato } & $y=0,2508 x+0,0113$ & 0,9404 & \multirow{3}{*}{$2,79( \pm 1,09)$} & \multirow{3}{*}{$21,16( \pm 10,80)$} \\
\hline & $y=0,5401 x+0,0172$ & 0,9196 & & \\
\hline & $y=0,3962 x+0,0401$ & 0,8899 & & \\
\hline \multirow{3}{*}{ Sulfato } & $y=0,0377 x+0,0008$ & 0,8727 & \multirow{3}{*}{$27,01( \pm 0,51)$} & \multirow{3}{*}{$44,57( \pm 3,03)$} \\
\hline & $y=0,0371 x+0,0009$ & 0,8488 & & \\
\hline & $y=0,0363 x+0,0008$ & 0,8284 & & \\
\hline \multirow{3}{*}{ Silicato } & $y=0,0092 x+0,00004$ & 0,8252 & \multirow{3}{*}{$110,76( \pm 8,88)$} & \multirow{3}{*}{$196,67( \pm 32,08)$} \\
\hline & $y=0,0083 x+0,00005$ & 0,8226 & & \\
\hline & $y=0,0097 x+0,00005$ & 0,8501 & & \\
\hline \multirow{3}{*}{ Fosfato } & $\mathrm{y}=0,0155 \mathrm{x}+0,0003$ & 0,9878 & \multirow{3}{*}{$65,80( \pm 1,14)$} & \multirow{3}{*}{$42,31( \pm 8,11)$} \\
\hline & $y=0,0151 x+0,0003$ & 0,9911 & & \\
\hline & $\mathrm{y}=0,0150 \mathrm{x}+0,0004$ & 0,9940 & & \\
\hline \multirow{3}{*}{ Oxalato } & $y=0,0255 x+0,0006$ & 0,9954 & \multirow{3}{*}{$39,38( \pm 0,71)$} & \multirow{3}{*}{$42,33( \pm 0,76)$} \\
\hline & $y=0,0258 x+0,0006$ & 0,9925 & & \\
\hline & $y=0,0249 x+0,0006$ & 0,9977 & & \\
\hline \multirow{3}{*}{ Citrato } & $y=0,0565 x-0,0014$ & 0,9679 & \multirow{3}{*}{$17,33( \pm 0,32)$} & \multirow{3}{*}{$65,32( \pm 44,59)$} \\
\hline & $y=0,0584 x-0,0005$ & 0,9925 & & \\
\hline & $y=0,0582 x-0,0015$ & 0,9879 & & \\
\hline
\end{tabular}

${ }^{(*)}$ Linearização da equação de Langmuir: $y=a+b x$, sendo $y=c / q, a=1 / k b_{(C M A)}, b=1 / b_{(C M A)}$ e $x=c \cdot{ }^{(* *)}$ Valores médios e desvios $(\mathrm{n}=3)$ calculados a partir de estimativas de $\mathrm{b}_{(\mathrm{CMA})}$ e k ( $\left.\mathrm{b}_{(\mathrm{CMA})} / \mathrm{a}\right)$ obtidas individualmente para cada repetição.

Latossolo Vermelho-Escuro, a qual aumentou de 0 a $3,5 \mathrm{mmol} \mathrm{kg}{ }^{-1}$ com a profundidade. Dynia ${ }^{31}$ associou a adsorção de nitrato ao fato de todos os solos terem apresentado aumento do número de cargas elétricas positivas em profundidade. Esse fato torna-se muito importante, em relação à contaminação de lençóis freáticos por nitrato, na medida em que o aumento da adsorção em maiores profundidades promove menor lixiviação para os lençóis, reduzindo a possibilidade de eutrofização de aqüíferos.

Do ponto de vista eletroquímico, existe uma grande diferença entre a adsorção de nitrato no solo e a de outros oxiânions, pois ele não é adsorvido via complexo de esfera interna, sendo sua adsorção apenas eletrostática, dependendo exclusivamente do balanço de cargas do solo. Embora esteja sendo "retido" na superfície da gibbsita, o valor médio encontrado para nitrato adsorvido em relação ao adicionado, em todas as concentrações utilizadas, representa apenas 3,8\% do total adicionado, o que comprova a baixa afinidade deste ânion pela superfície adsorvente, na presença de uma solução de fundo contendo cloreto. Isso ficou demonstrado pelo menor valor de b(CMA) encontrado para este ânion (2,8 mmol kg-1) em comparação com os demais. A presença de cargas positivas tende a ser maior em solos de regiões tropicais úmidas, com menores teores de matéria orgânica e estádio de intemperismo-lixiviação mais avançado que em solos de regiões temperadas. Assim, nestas condições, a lixiviação de nitrato tende a ser dificultada, embora não totalmente impedida. Estes dados estão em consonância com os de Guedes et al..$^{32}$ e Araújo et al..$^{33}$

Neste estudo, a CMA de sulfato foi de $27,0 \mathrm{mmol} \mathrm{kg} \mathrm{e}^{-1}$ os teores de sulfato adsorvido aumentaram de 6 a $40 \mathrm{mmol} \mathrm{kg}^{-1}$ de gibbsita (Figura 3). Embora este ajuste tenha sido feito e a repetibilidade dos dados de b e k tenha sido boa (Tabela 1), notou-se que o ponto máximo da isoterma da CMA não foi atingido. Vale lembrar que, para sulfato, as concentrações molares utilizadas foram equivalentes à metade daquelas usadas para os demais ânions, pois foi considerado que cada mol de sulfato representa 2 moles de carga do ânion. Assim, a dose proposta deve ter sido insuficiente para se atingir a CMA. Em solos do estado de São Paulo, Alves ${ }^{34}$ encontrou valores médios de CMA de sulfato de $17 \mathrm{mmol} \mathrm{kg}^{-1}$, teores de sulfato ad-

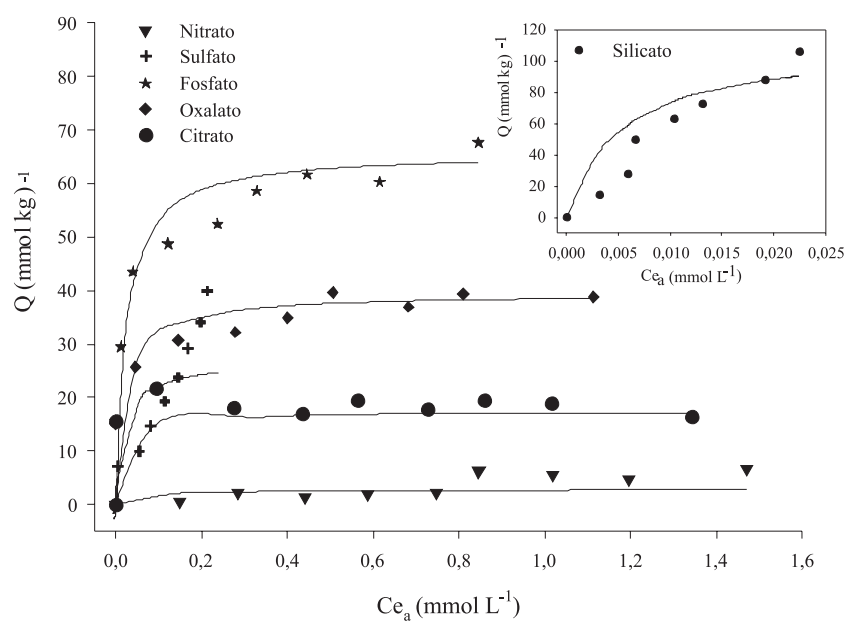

Figura 3. Relação entre a quantidade adsorvida $\left(Q\right.$, mmol $\left.\mathrm{kg}^{-1}\right)$ e a concentração de equilíbrio no sobrenadante $\left(\mathrm{Ce}_{a^{\prime}} \mathrm{mmol} \mathrm{L}^{-1}\right)$ para diferentes ânions em gibbsita pedogenética (relação gibbsita:solução 1:100; pH inicial 5,5 \pm 0,2; força iônica $30 \mathrm{mmol} \mathrm{L}^{-1}$ como $\mathrm{NaCl}$ ). Pontos indicam dados experimentais observados em triplicata. As linhas foram obtidas a partir das equações de Langmuir, cujos parâmetros são mostrados na Tabela 1 
sorvido variando de 6 a $44 \mathrm{mmol} \mathrm{kg}^{-1}$ de argila; a maior capacidade adsortiva foi observada para o Latossolo Amarelo ácrico e a menor para o Argissolo Vermelho-Amarelo distrófico. Esses resultados estão associados à mineralogia diferencial da fração argila desses solos, principalmente gibbsita e óxidos de $\mathrm{Al}$ mal cristalizados no primeiro caso, e caulinita no segundo. Essa associação foi também destacada por Aylmore et al..$^{35}$

A dinâmica de Si pode ser explicada pela cinética das reações de adsorção e dessorção, as quais podem ser rápidas, controlando-se os níveis de silício em solução. De acordo com McKeague e Cline, ${ }^{36}$ vários compostos comuns nos solos são capazes de adsorver silício, entre os quais eles a gibbsita. Embora a CMA tenha sido maior para o silicato $\left(110,8 \mathrm{mmol} \mathrm{kg} \mathrm{kg}^{-1}\right)$ em relação ao fosfato $\left(65,8 \mathrm{mmol} \mathrm{kg}{ }^{-1}\right)$ (Tabela 1), a dessorção média daquele foi bem maior $(81,9 \%)$ que a deste (Figura 4). Curi e Franzmeier ${ }^{13}$ dentre outros, realçaram a elevada capacidade de adsorção de fosfato em solos mais oxídicos.

Para solos de mesmo $\mathrm{pH}$, a quantidade de silicato na solução do solo varia em função da quantidade, tipo e grau de cristalinidade dos óxidos de $\mathrm{Fe}$ e de $\mathrm{Al}$ livres. Quando se comparam óxidos de ferro e de alumínio com mesmo grau de cristalinidade, é notória a maior eficiência do óxido de alumínio em adsorver ácido monossilícico, comparativamente ao óxido de ferro. ${ }^{37}$ Korndörfer et al. ${ }^{38}$ avaliaram quatro solos das classes Latossolo Vermelho-Escuro álico (LEa), Latossolo Vermelho-Amarelo álico (LVa), Latossolo Roxo distrófico (LRd) e Areia Quartzosa álica (AQa) quanto à capacidade de adsorção de silicato aplicado na forma de silicato de cálcio e observaram maior adsorção nos solos LEa e LVa, comparados aos demais, atribuindo esse fato aos valores mais altos de $\mathrm{Al}_{2} \mathrm{O}_{3}$ encontrados naqueles solos.

A adsorção de fosfato é a adsorção aniônica mais intensamente estudada em ciência do solo. ${ }^{39}$ Em solos com predomínio de carga variável, o fosfato é o ânion mais fortemente adsorvido através de complexos de esfera interna..$^{40}$ Os óxidos de alumínio são os principais responsáveis pela adsorção de grande parte do fosfato aplicado nos solos oxídicos. ${ }^{41}$ Portanto, em função da elevada capacidade de retenção de fósforo nesses solos, são necessárias aplicações de maiores doses do ânion para se atingirem níveis adequados ao desenvolvimento das plantas, principalmente no início da exploração agrícola ${ }^{42}$ período de maior exigência do nutriente pelas culturas. Solos cultivados por longos períodos, tendo recebido calagens e adubações fosfatadas periódicas, apresentam menor capacidade de adsorção de fosfato que seus equivalentes não cultivados. ${ }^{43}$ Naquele trabalho, ${ }^{42}$ os valores de capacidade máxima de adsorção de fosfato calculados com a isoterma de Langmuir foram 10,4 e 96,7 mmol $\mathrm{kg}^{-1}$, para solos cultivados e não cultivados, respectivamente. No

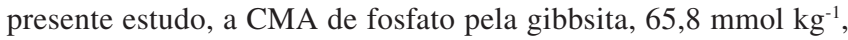
encontrou-se nesse intervalo (Tabela 1), estando mais próxima à de solos não cultivados. Adotando como referência a classificação proposta por Juo e Fox ${ }^{44}$ para adsorção de $\mathrm{P}$ em solos tropicais, a capacidade de adsorção de fosfato pela gibbsita deste estudo pode ser enquadrada como muito alta, com valores de CMA muito maiores que $32,3 \mathrm{mmol} \mathrm{P} \mathrm{kg}{ }^{-1}$, muito embora o $\mathrm{PCZ}(6,4)$ seja bem mais baixo que aquele de óxidos de $\mathrm{Al}$ sintéticos $(9,5-10,0),{ }^{45}$ sugerindo a ocorrência de complexos de esfera interna no processo adsortivo, em concordância com Marsh et al.. ${ }^{40} \mathrm{~A}$ gibbsita tem participação importante na adsorção de fósforo, embora de forma menos efetiva que a goethita, ${ }^{46}$ possivelmente pela menor superfície específica daquela. Em razão da sua presença em grandes quantidades em alguns Latossolos argilosos oxídicos muito velhos, a contribuição da gibbsita, em termos de adsorção total, pode, porém, ultrapassar a dos óxidos de ferro. ${ }^{47} \mathrm{~A}$ atuação da caulinita em relação aos componentes oxídicos no processo de adsorção de $\mathrm{P}$ tende a ser menos expressiva. ${ }^{43}$
Os ácidos orgânicos alifáticos selecionados para este estudo (cítrico e oxálico) diferem entre si com respeito ao número de grupos carboxila, comprimento da cadeia carbônica, valores de $\mathrm{pK}$ e número de grupos hidroxila. ${ }^{48} \mathrm{O}$ parâmetro CMA indicou que na gibbsita o oxalato $\left(39,4 \mathrm{mmol} \mathrm{kg}^{-1}\right)$ foi mais adsorvido que o citrato $(17,3 \mathrm{mmol}$ $\mathrm{kg}^{-1}$ ) (Tabela 1), estando de acordo com Marchi et al. ${ }^{21}$ que trabalharam com solos de carga variável. Obtiveram valores máximos de CMA de oxalato em torno de $64,0 \mathrm{mmol} \mathrm{kg}{ }^{-1}$ no horizonte A de Latossolo Vermelho e valores de citrato de $39,2 \mathrm{mmol} \mathrm{kg}^{-1} \mathrm{em}$ horizonte B de Latossolo Vermelho-Amarelo, ambos de textura muito argilosa e nos quais foram obtidos os maiores valores de CMA destes ânions.

Segundo Liu et al., ${ }^{49}$ na goethita a pH 4,0, a adsorção de fosfato é maior que a de sulfato e oxalato. A mesma tendência foi observada aqui. Entretanto, os valores de CMA encontrados na goethita daquele trabalho foram muito maiores $\left(257,6 \mathrm{mmol} \mathrm{kg}^{-1}\right.$ para fosfato, 162,4 mmol kg-1 para oxalato e $115,9 \mathrm{mmol} \mathrm{kg}^{-1}$ para sulfato) que na gibbsita deste estudo $\left(65,8 \mathrm{mmol} \mathrm{\textrm {kg } ^ { - 1 }}\right.$ para fosfato, $39,4 \mathrm{mmol} \mathrm{kg} \mathrm{m}^{-1}$ para oxalato e $27,0 \mathrm{mmol} \mathrm{kg}^{-1}$ para sulfato). A menor superfície específica da gibbsita em relação à goethita ajuda a explicar tais resultados.

\section{Dessorção aniônica individual}

A proporção do nitrato dessorvido em relação ao adsorvido variou pouco com as doses adicionadas (14,8 a 23,3\%) (Figura 4). Assim pode-se depreender que a dessorção foi praticamente independente da dose, ou seja, a "força" de retenção foi semelhante em todas as doses adicionadas. Esta dessorção percentual relativamente pequena poderia sugerir a ocorrência de complexos de esfera interna, mas pouco nitrato havia sido adsorvido previamente (Tabela 1). Dynia e Camargo ${ }^{50}$ observaram aumento na capacidade de adsorção de nitrato com a profundidade em solos de carga variável, devido ao maior número de cargas elétricas positivas e ao menor teor de matéria orgânica das camadas subsuperficiais em relação às superficiais. Tomando-se como exemplo a testemunha daquele trabalho ${ }^{50}$ com valores de capacidade de adsorção de nitrato iguais a 0,8 e $1,8 \mathrm{mmol} \mathrm{kg}^{-1}$ nas camadas de 20-40 e 40-60 cm, respectivamente, eles verificaram que as camadas em conjunto (20-60 $\mathrm{cm}$ de profundidade) seriam capazes de reter aproximadamente $70 \mathrm{~kg} \mathrm{ha}^{-1}$ de $\mathrm{N}$. Neste trabalho, considerando-se

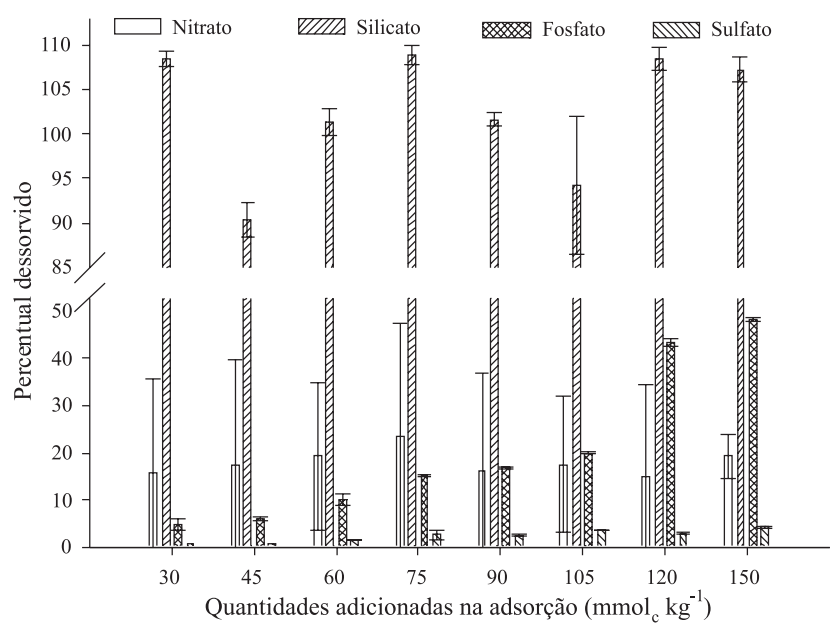

Figura 4. Percentual dessorvido dos ânions inorgânicos nitrato, silicato, fosfato e sulfato $\left[\hat{\text { Annion }}{ }_{\% \text { desorvida }}=\left(\hat{\text { Annion }}{ }_{\text {dessorvido }} / \hat{\text { Ânion }}{ }_{\text {adsorvido }}\right) \times 100\right]_{\text {adsorvidos }}$ em gibbsita pedogenética (relação gibbsita: solução 1:100; pH inicial 5,5 \pm 0,2; força iônica $30 \mathrm{mmol} \mathrm{L}^{-1}$ como $\mathrm{NaCl}$ ) em função das doses adicionadas dos mesmos. A coluna representa a média e suas respectivas barras os desvios padrão calculados por três repetições 
a camada em que foi coletada a gibbsita $(65-90 \mathrm{~cm}$ de profundidade) e ainda que cerca de $80 \%$ da CMA de nitrato $\left(2,8 \mathrm{mmol} \mathrm{kg}^{-1}\right)$ restaria após a dessorção, então a capacidade de armazenamento de $\mathrm{N}$ na forma de nitrato nesta camada, seria de $92 \mathrm{~kg} \mathrm{ha}^{-1}$ (densidade do solo $=1,17 \mathrm{~g} \mathrm{~cm}^{-3}$ ). Isso corrobora as observações de $S a n c h e z^{51} \mathrm{de}$ que algumas áreas de solos tropicais em subsuperfície são capazes de reter cerca de $100 \mathrm{~kg} \mathrm{ha}^{-1}$ de $\mathrm{N}$ na forma de nitrato. Levando-se em consideração a grande profundidade dos Latossolos gibbsíticos das chapadas da região dos cerrados, estudados por Marques et al. ${ }^{14}$ e os dados obtidos neste trabalho, a preocupação com a eutrofização das águas e o comprometimento da sustentabilidade do sistema perde grande parte de sua relevância no caso deste ânion.

Com o aumento das doses adicionadas de sulfato, a porcentagem de dessorção aumentou ( 0 a 4,2\%), isto é, a gibbsita somente libera o ânion com o aumento das quantidades adicionadas (Figura 4). A dessorção do sulfato pelas amostras de solo do estado de São Paulo variou de 4,8\% para o Latossolo Amarelo ácrico a 28,4\% para o Nitossolo Vermelho eutroférrico, com um valor médio de $12,4 \%$ para o conjunto das amostras avaliadas. Os Latossolos Vermelho acriférrico e Amarelo ácrico apresentaram menores percentuais de dessorção, devido à composição predominantemente oxídica de suas frações argila. Teores elevados de caulinita favorecem a dessorção de sulfato, ao contrário do observado para a gibbsita e os óxidos de alumínio mal cristalizados. ${ }^{34}$ Ao analisarem-se os fatores que interferem na dessorção de sulfato, pode-se perceber alguma relação com os mecanismos de adsorção. Curtin e Syers ${ }^{52}$ verificaram que o aumento da força iônica da solução mostrou-se capaz de intensificar a dessorção de sulfato.

A proporção dessorvida de silicato permaneceu aproximadamente constante $( \pm 100 \%)$ com o aumento da dose adicionada (Figura 4), ou seja, para qualquer dose adicionada, com a mesma facilidade que a gibbsita adsorve, ela dessorve o silicato, o que é típico de adsorção via complexos de esfera externa. Isso pode estar relacionado ao fato de que a pH 5,5 o silicato não possui carga, sendo facilmente deslocado após um tempo de equilíbrio de adsorção (24 h). O valor médio de silicato adsorvido $\left(69 \mathrm{mmol} \mathrm{kg}^{-1}\right)$ foi dessorvido (71 mmol kg-1). Dessa forma, embora o silicato seja o ânion com maior CMA (110 mmol kg-1) (Tabela 1), ele também é o dessorvido em maior quantidade (Figura 4). $\mathrm{O}$ fosfato adsorvido $\left(67,6 \mathrm{mmol} \mathrm{kg}^{-1}\right)$ na maior dose adicionada $\left(1,5 \mathrm{mmol} \mathrm{L}^{-1}\right)$ foi $48,4 \%$ maior que o dessorvido $\left(32,7 \mathrm{mmol} \mathrm{kg}^{-1}\right)$ na mesma dose (Figura 4), ou seja, mais de $50 \%$ do fosfato adsorvido ficou retido na gibbsita e não foi liberado para a solução. Observou-se aumento do percentual de dessorção com o aumento da dose adicionada, indicando ter havido "saturação" nas doses maiores, facilitando a retirada do fosfato previamente adsorvido, ou seja, aparentemente existe um limite $(\sim 50 \%)$ para o percentual do $\mathrm{P}$ adicionado que se mantém adsorvido após a dessorção. A dessorção dos ânions pelos minerais de argila permite avaliar o grau de reversibilidade das reações de adsorção, um fator de extrema importância nos solos tropicais, ${ }^{53}$ devido à baixa disponibilidade de fosfato nos mesmos. ${ }^{54}$ Estes últimos autores observaram maior adsorção e menor dessorção em solos mais goethíticos, comparados aos mais gibbsíticos, em função do menor tamanho de partícula da goethita em relação à gibbsita.

\section{CONCLUSÕES}

A gibbsita do presente trabalho é de elevada cristalinidade, conforme evidenciado pela difratometria de raios-X e pela baixa área superficial específica. Apesar disso, encontraram-se altas capacidades de adsorção para os ânions nitrato, silicato, fosfato, sulfato, citrato e oxalato.
Apesar de a adsorção de nitrato pela gibbsita ter sido menor que as adsorções dos demais ânions estudados, a reação envolvendo nitrato mostrou ter baixa reversibilidade. A dessorção de silicato pela gibbsita foi intensa e independente da quantidade previamente adsorvida, enquanto que o contrário foi observado para o fosfato. A adsorção de fosfato pela gibbsita pedogenética foi classificada como muito alta, mesmo em condição de valor de $\mathrm{pH}$ inferior ao $\mathrm{PCZ}$ reportado para óxidos de $\mathrm{Al}$ sintéticos.

\section{AGRADECIMENTOS}

À Fundação de Amparo à Pesquisa de Minas Gerais - FAPEMIG, pela concessão da bolsa de estudos da primeira autora e ao $\mathrm{CNPq}$ pelo financiamento da pesquisa.

\section{REFERÊNCIAS}

1. Hingston, F. J.; Posner, A. M.; Quirk, J. P.; Soil Sci. 1974, 25, 16.

2. Sparks, D.L.; Environmental soil chemistry, Academic Press: San Diego, 1995.

3. Essington, M. E.; Soil and water chemistry, CRC Press: Boca Raton, 2004.

4. Meurer, E. J., ed.; Fundamentos de Química do Solo, $3^{\mathrm{a}}$ ed., Evangraf: Porto Alegre, 2006.

5. Rajan, S. S. S.; Soil Sci. 1978, 42, 39.

6. Hsu, P. H. Em Minerals in soil environments; Dixon, J. B.; Weed, S. B., eds.; SSSA: Madison, 1989.

7. Chao, T. T.; Harward, M. E.; Fang, S. C.; Soil Sci. 1962, 94, 276.

8. Fassbender, H. W.; Quimica del suelos con énfasis en suelos de América Latina, $2^{a}$ ed., ILCA: San José, 1987.

9. Leite, P. C.; Tese de Doutorado, Universidade Federal de Viçosa, Brasil, 1997.

10. Barnhisel, R. I.; Rich, C. I.; Soil Sci. 1965, 29, 531.

11. Schoen, R.; Roberson, C. E.; Am. Mineral. 1970, 55, 43.

12. Kodama, H.; Schnitzer, M.; Geoderma 1980, 24, 195.

13. Curi, N.; Franzmeier, D. P.; Soil Sci. 1984, 48, 341.

14. Marques, J. J. S. M.; Schulze, D. G.; Curi, N.; Mertzman, S. A.; Geoderma 2004, 119, 179.

15. Gomes, J. B. V.; Curi, N.; Motta, P. E. F.; Ker, J. C.; Marques, J. J. G. S. M.; Schulze, D. G.; R. Bras. Ci. Solo 2004, 28, 137.

16. Huang, P. M.; Wang, M. K.; Kämpf, N.; Schulze, D. G. Em Soil Mineralogy with Environmental Applications; SSSA: Madison, 2002.

17. Motta, P. E. F.; Kämpf, N.; Z. Pflanzenernähr und Bodenk. 1992, 155, 385.

18. Schwertmann, U.; Z. Pflanzenernähr und Bodenkd. 1964, 105, 105.

19. Resende, M.; Thesis Ph.D.; Purdue University, EUA, 1976.

20. Resende, M.; Curi, N.; Ker, J. C.; Rezende, S. B.; Mineralogia de solos brasileiros: interpretação e aplicações, $1^{\mathrm{a}}$ ed., Editora UFLA: Lavras, 2005.

21. Marchi, G.; Guilherme, L. R. G.; Lima, J. M.; Chang, A. C.; Fontes, R. L.; Comm. Soil Sci. Plant Anal. 2006, 37, 1367.

22. Murphy, J.; Riley, J. P.; Anal. Chim. Acta 1962, 27, 31.

23. Cornell, R. M.; Schwertmann, U.; The Iron Oxides, $3^{\text {rd }}$ ed., Weinheim-VHC: New York, 2003.

24. Molis, E.; Barre`s, O.; Marchand, H.; Sauze`at, E.; Humbert, B.; Thomas, F.; Colloids and Surfaces, A: Physicochemical and Engineering Aspects 2000, 163, 283.

25. Veith, J. A.; Sposito, G.; Soil Sci. 1977, 41, 697.

26. Rietra, R. P. J. J.; Hiemstra, T.; Riemsdijk, W. H.; Geochim. Cosmochim. Acta 1999, 63, 3009.

27. Sposito, G.; The chemistry of soils, Oxford University Press: New York, 1989.

28. Griffin, R. A.; Jurinak, J. J.; Soil Sci. 1973, 11, 26. 
29. Gustaffson, J. P.; Visual Minteq, ver.2.50, KTH. Stockolm, Sweden Department of Land and Water Resorces Engeenering, 2006.

30. Oliveira, J. R. A.; Vilela, L.; Ayarza, M. A.; R. Pesq. Agrop. Bras. 2000, $35,1199$.

31. Dynia, J. F.; Comm. Soil Sci. Plant Anal. 2000, 31, 777.

32. Guedes, G. A. A.; Moura Filho, W.; Fontes, L. A. N.; R. Ceres 1979, 26, 65 .

33. Araújo, A. R.; Carvalho, J. L. N.; Guilherme, L. R. G.; Curi, N.; Marques, J. J. G. S. M.; Ci \& Agrotec. 2004, 28, 541.

34. Alves, M. E.; Tese de Doutorado, Universidade de São Paulo, Brasil, 2002.

35. Aylmore, L. A. G.; Mesbahul, K.; Quirk, J. P.; Soil Sci. 1967, 103, 10.

36. McKeague, J. A.; Cline, M. G.; Adv. Agron. 1963, 15, 339.

37. Jones, L. H. P.; Handreck, K. A.; Nature 1963, 108, 852.

38. Korndörfer, G. K.; Arantes, V. A.; Corrêa, G. F.; Snyder, G. H.; R. Bras. Ci. Solo 1999, 23, 623.

39. Zhang, G. Y.; Yu, T. R. Em Chemistry of Variable Charge Soils; Yu, T. R., ed.; Oxford University Press: New York, 1997.

40. Marsh, K. B.; Tillman, R. W.; Syers, J. K.; Soil Sci. 1987, 51, 318.

41. Bahia Filho, A. F. C.; Braga, J. M.; Resende, M.; Ribeiro, A. C.; R. Bras. Ci. Solo 1983, 7, 221.

42. Reis, C.; Fabris, J. D.; Novais, R. F.; Bahia Filho, A. F. C.; Santana, D. P.; Curi, N.; Coey, J. M. D.; R. Bras. Ci. Solo 1995, 19, 337.
43. Motta, P. E. F.; Curi, N.; Siqueira, J. O.; Van Raij, B.; Neto, A. E. F.; Lima, J. M.; R. Bras. Ci. Solo 2002, 26, 349.44.

44. Juo, A. S. R.; Fox, R. L.; Soil Sci. 1977, 24, 370.

45. Goldberg, S.; Davis, J. A.; Hem, J. D. Em The environmental chemistry of aluminum; Sposito, G.. ed.; CRC Press/Lewis Publ.: Boca Raton, 1996.

46. McLaughlin, R. B.; Ryden, J. C.; Syers, J. R.; Soil Sci. 1981, 32, 65.

47. Mesquita Filho, M. V.; Torrent, J.; Geoderma 1993, 58, 107.

48. Skoog, D. A.; West, D. M.; Holler, F. J.; Fundamentals of Analytical Chemistry, $7^{\text {th }}$ ed., Saunders College Publishing: New York, 1997.

49. Liu, F.; He, J.; Colombo, C.; Violante, A.; Soil Sci. 1999, 164, 180.

50. Dynia, J. F.; Camargo, O. A.; R. Pesq. Agrop. Bras. 1999, 34, 141.

51. Sanchez, P.A. Em Plant-soil interactions at low pH: Sustainable agriculture and forestry production; Moniz, A. C.; Furlani, A. M. C.; Schaffert, R. E.; Fageria, N. K.; Rosolem, C. A.; Catarella, H.; eds.; SBCS: Campinas/Viçosa, 1997.

52. Curtin, D.; Syers, J. K.; Soil Sci. 1990, 41, 305.

53. Cabrera, F.; De Arambarri, P.; Madrid, L.; Toca, C. G.; Geoderma 1981, 26, 203.

54. Souza, J. A.; Curi, N.; Guedes, G. A. A.; Ci. \& Agrotec. 1991, 15, 103.

55. Pozza, A. A. A.; Curi, N.; Costa, E. T. S.; Guilherme, L. R. G.; Marques, J. J. G. S. M.; Motta, P. E. F.; R. Pesq. Agrop. Bras. 2007, 42, 1627. 